\title{
Identification and Regulation of the Cystic Fibrosis Transmembrane Conductance Regulator-Generated Chloride Channel
}

\author{
Herbert A. Berger," Matthew P. Anderson," Richard J. Gregory," Simon Thompson," Paul W. Howard," Richard A. Maurer," \\ Richard Mulligan, Alan E. Smith," and Michael J. Welsh* \\ ${ }^{*}$ Howard Hughes Medical Institute, Departments of Internal Medicine and "Physiology and Biophysics, University of Iowa College of \\ Medicine, Iowa City, Iowa 52242; ' Genzyme Corporation, Framingham, Massachusetts 01701; and ${ }^{8}$ Whitehead Institute, \\ Cambridge, Massachusetts 02142
}

\begin{abstract}
Cystic fibrosis transmembrane conductance regulator (CFTR) generates cAMP-regulated $\mathrm{Cl}^{-}$channels; mutations in CFTR cause defective $\mathrm{Cl}^{-}$channel function in cystic fibrosis epithelia. We used the patch-clamp technique to determine the single channel properties of $\mathrm{Cl}^{-}$channels in cells expressing recombinant CFTR. In cell-attached patches, an increase in cellular cAMP reversibly activated low conductance $\mathrm{Cl}^{-}$channels. cAMP-dependent regulation is due to phosphorylation, because the catalytic subunit of cAMP-dependent protein kinase plus ATP reversibly activated the channel in excised, cell-free patches of membrane. In symmetrical $\mathrm{Cl}^{-}$solutions, the channel had a channel conductance of $10.4 \pm 0.2(n=7)$ pS and a linear current-voltage relation. The channel was more permeable to $\mathrm{Cl}^{-}$than to $\mathrm{I}^{-}$and showed no appreciable time-dependent voltage effects. These biophysical properties are consistent with macroscopic studies of $\mathrm{Cl}^{-}$channels in single cells expressing CFTR and in the apical membrane of secretory epithelia. Identification of the single channel characteristics of CFTR-generated channels allows further studies of their regulation and the mechanism of ion permeation. (J. Clin. Invest. 1991. 88:1422-1431.) Key words: cystic fibrosis • patch-clamp - phosphorylation $\cdot \mathrm{Cl}^{-}$secretion • cAMP
\end{abstract}

\section{Introduction}

Cystic fibrosis $(C F)^{1}$ is a genetic disease (1), characterized by defective function of $\mathrm{Cl}^{-}$channels in affected epithelia: in $\mathrm{CF}$ secretory epithelia, an increase in intracellular cAMP fails to

Address correspondence to Michael Welsh, M.D., Howard Hughes Medical Institute, 500 EMRB, University of Iowa College of Medicine, Iowa City, IA 52242.

Received for publication 31 May 1991 and in revised form 17 July 1991.

1. Abbreviations used in this paper: CF, cystic fibrosis; CFTR, cystic fibrosis transmembrane regulator, IBMX, 3-isobutyl-1-methyl-xanthine; NMDG-Cl, $N$-methyl-D-glucamine chloride; PKA, protein kinase; TES, $N$-Tris(hydroxymethyl)methyl-2-aminoethane sulfonic acid.

J. Clin. Invest.

(c) The American Society for Clinical Investigation, Inc.

0021-9738/91/04/1422/10 $\$ 2.00$

Volume 88, October 1991, 1422-1431 open apical membrane $\mathrm{Cl}^{-}$channels $(1,2)$. Expression of wildtype CF transmembrane conductance regulator (CFTR) (3) in CF epithelia corrects the defect in cAMP-regulated $\mathrm{Cl}^{-}$permeability $(4,5)$. Moreover, expression of CFTR generates cAMPregulated $\mathrm{Cl}^{-}$channels in a variety of cells that do not normally express CFTR and do not normally have cAMP-regulated $\mathrm{Cl}^{-}$ channels $(6,7)$. These observations are explained by recent studies which demonstrate that CFTR is itself a cAMP-regulated $\mathrm{Cl}^{-}$channel: mutation of amino acids in the membrane spanning sequences of CFTR alter its anion selectivity (8).

Previous studies showing that CFTR generates $\mathrm{Cl}^{-}$channels relied primarily on the whole cell patch-clamp technique to measure macroscopic channel currents (6-8). However, it is also important to define the single channel properties, so that they can be compared to those of previously reported channels, and so that the excised, patch-clamp technique can be used in future studies of channel biophysics and regulation. To examine the single channel properties, we expressed CFTR in cells that do not normally express CFTR and do not normally have cAMP-regulated $\mathrm{Cl}^{-}$channels (6). Two different cell types (HeLa cells and 3T3 fibroblasts) and two different expression systems (transient and stable) were used.

We also asked whether CFTR-generated $\mathrm{Cl}^{-}$channels are regulated by phosphorylation with the CAMP-dependent protein kinase (PKA). Several observations suggested that PKAdependent phosphorylation would regulate this $\mathrm{Cl}^{-}$channel: the amino acid sequence of CFTR has multiple potential phosphorylation sites for PKA (3); CFTR is a phosphoprotein (9); an increase in intracellular cAMP activates $\mathrm{Cl}^{-}$channels studied with the whole cell patch-clamp technique (4-8); and deletion of the majority of the potential phosphorylation sites generates channels that are open even without an increase in cAMP (9). Those observations did not, however, tell us whether phosphorylation activated the $\mathrm{Cl}^{-}$channel or whether cAMP itself might regulate the $\mathrm{Cl}^{-}$channel in a manner analogous to cyclic nucleotide-gated channels in photoreceptors and olfactory receptors (10). To test the hypothesis that the CFTR-generated $\mathrm{Cl}^{-}$channels are regulated by phosphorylation, we examined the effect of the catalytic subunit of cAMP-dependent protein kinase on $\mathrm{Cl}^{-}$channels in excised, cell-free patches.

\section{Methods}

Cells and transfection procedure. We used HeLa cells and NIH 3T3 fibroblasts; in previous studies we have shown that these cells do not express CFTR (by polymerase chain reaction, by immunoprecipitation, or by function $[6,11])$. To transiently express CFTR in HeLa 




B

a

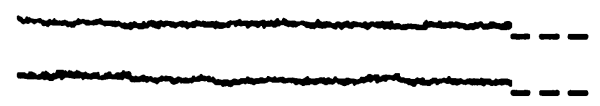

b

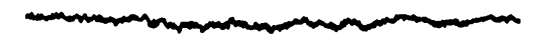

- -
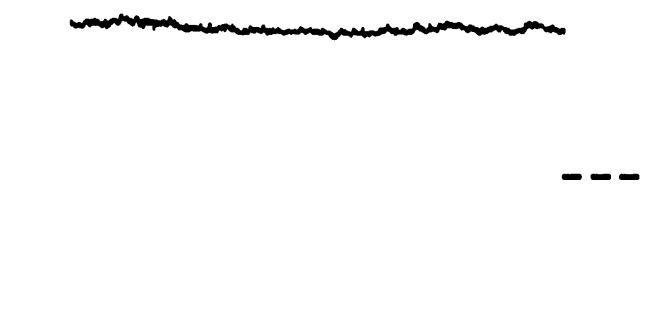

C

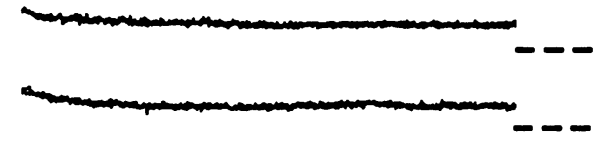

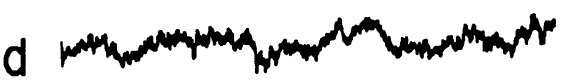
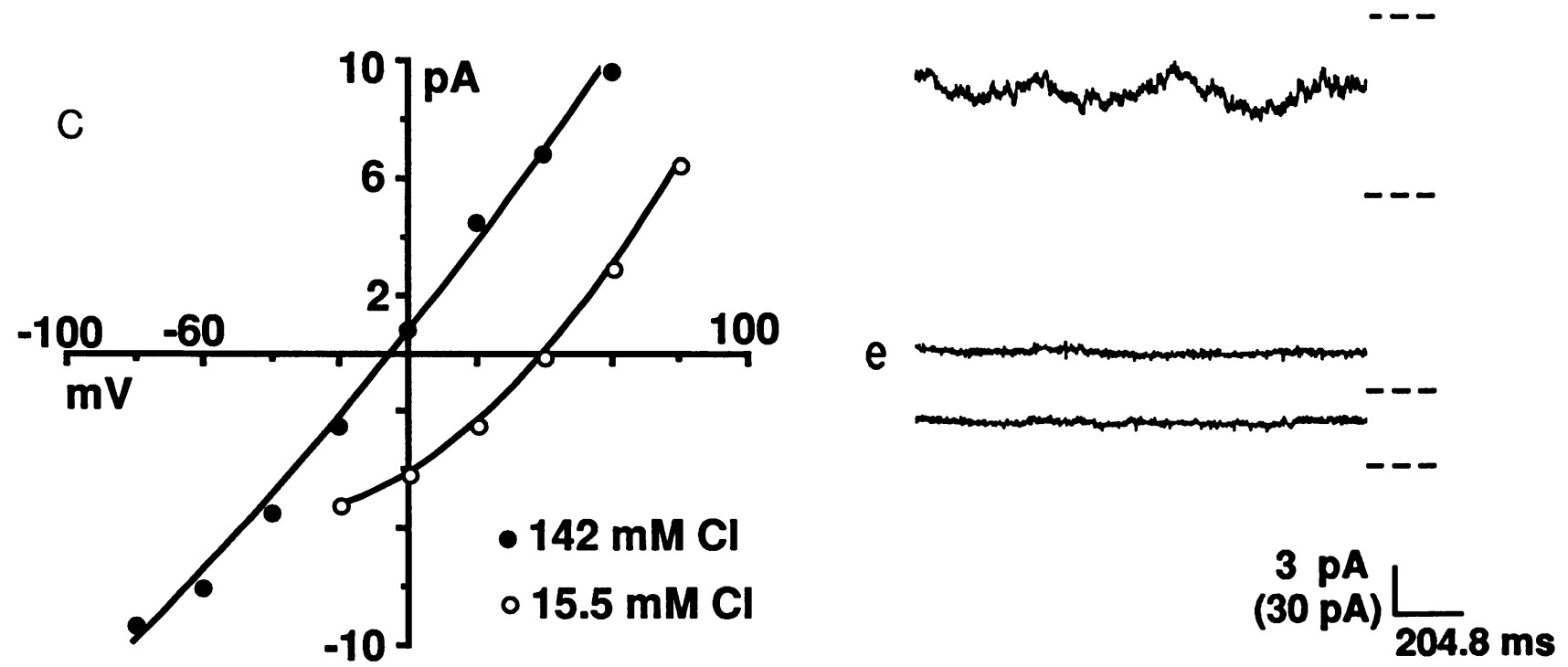

Figure 1. Expression of CFTR induces cAMP-activated $\mathrm{Cl}^{-}$currents in cell-attached patches from 3T3-CFTR fibroblasts. $(A)$ Time course of changes in current produced by addition of $100 \mu \mathrm{M}$ IBMX and $20 \mu \mathrm{M}$ forskolin (cAMP, as indicated by bars). Membrane voltage was maintained at $-40 \mathrm{mV}$ and stepped to $+40 \mathrm{mV}$ for $1 \mathrm{~s}$ every $6 \mathrm{~s}$. Data points are average current obtained during the $1-\mathrm{s}$ pulse to $+40 \mathrm{mV}$. ${ }^{*}$ Time at which $\mathrm{I}-\mathrm{V}$ relation in $1 C$ was obtained. $(B)$ Current traces obtained at the times indicated by the lower case letters in A. All traces were obtained at +40 $\mathrm{mV}$, two traces are shown for each condition. Scale bar for traces in $b$ are $30 \mathrm{pA}$ and $3 \mathrm{pA}$ for all other traces. Dashed line indicates zero current. $(C)$ I-V relation from cell-attached patches. I-V relation indicated by closed symbols is from data shown in Fig. $1, A$ and $B$. Pipette solution contained $142 \mathrm{mM} \mathrm{Cl}^{-}$and $140 \mathrm{mM}$ NMDG. I-V relation indicated by open symbols was obtained from a different cell in which pipette contained $15.5 \mathrm{~m} \mathrm{M} \mathrm{Cl}^{-}$. For both traces, basal currents (before addition of cAMP) were subtracted from values after addition of forskolin and IBMX. 


\section{A}
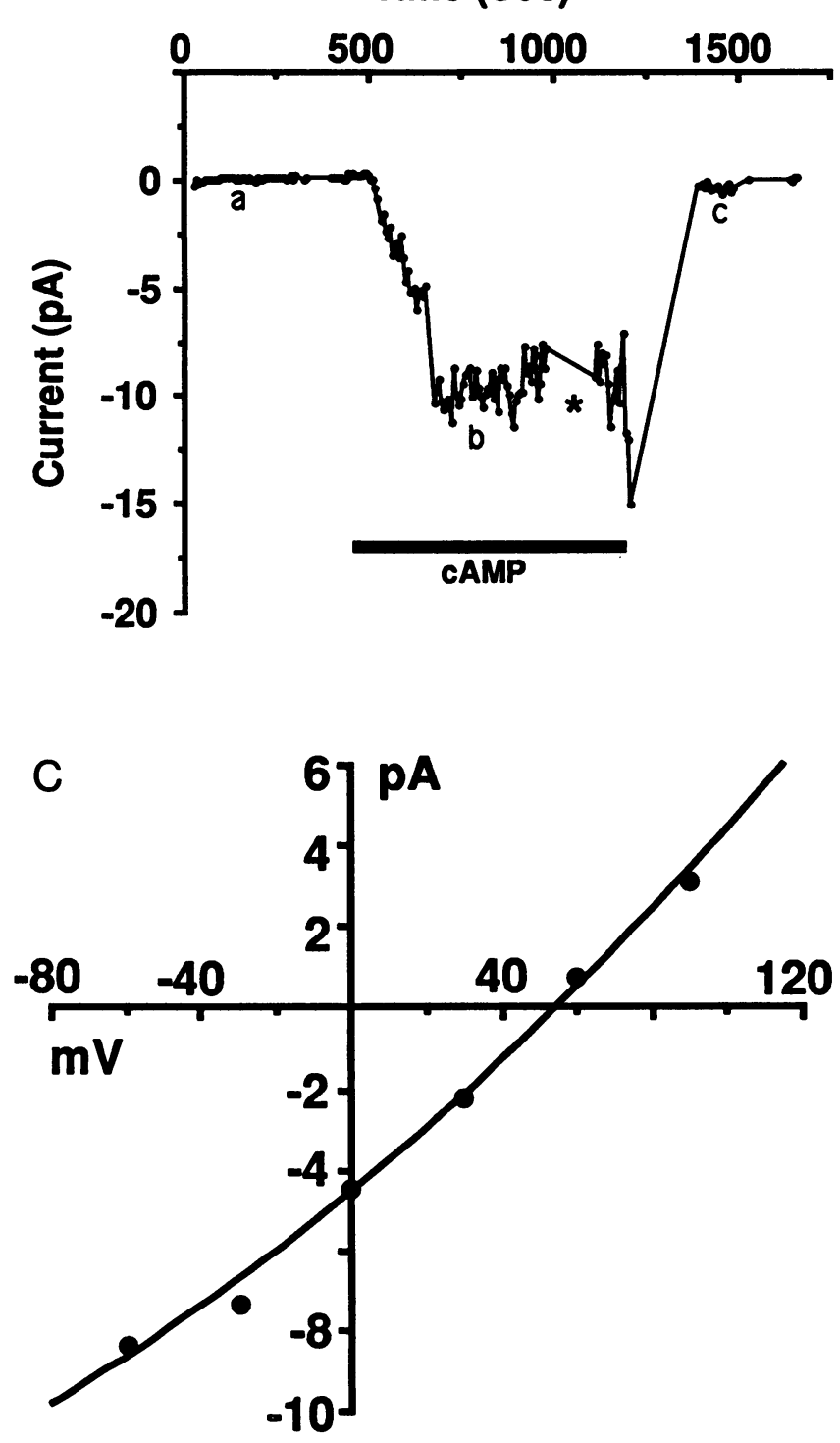

B

a

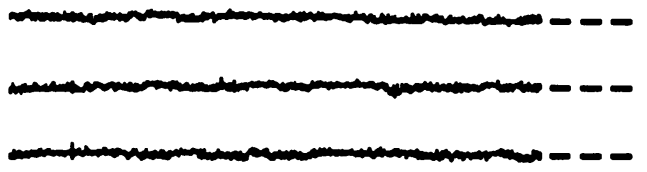

b

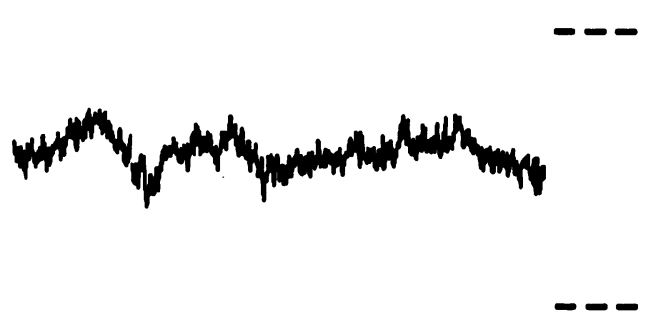

(n)

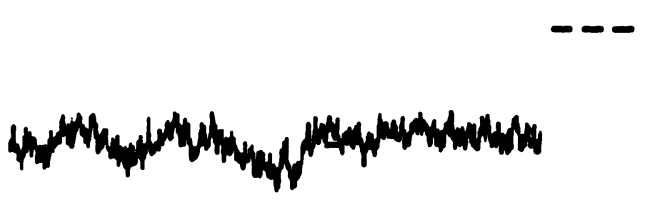

C

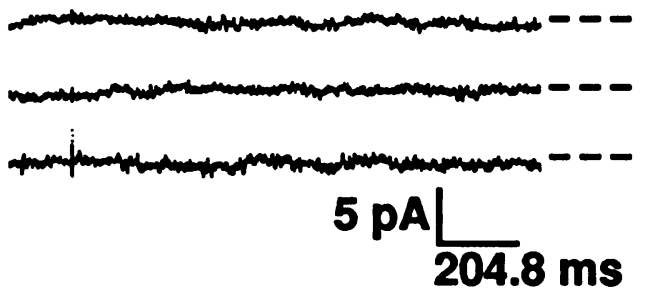

Figure 2. Expression of CFTR induces cAMP-regulated $\mathrm{Cl}^{-}$currents in cell-attached patches HeLa cells. $(A)$ Time course of activation in response to $100 \mu \mathrm{M}$ IBMX and $20 \mu \mathrm{M}$ forskolin (present during times indicated by bar cAMP). Pipette contained $14 \mathrm{mM} \mathrm{Cl}^{-}, 136 \mathrm{mM}^{2}$ aspartic acid, and $140 \mathrm{mM}$ NMDG. Data points indicate average current during a $1-\mathrm{s}$ pulse to $-60 \mathrm{mV}$ from a holding voltage of $0 \mathrm{mV}$. (B) Representative traces obtained at the times indicated by the lower case letters in $A$. Voltage was $-60 \mathrm{mV}$. Dashed line indicates zero current. (C) I-V relation obtained at the time indicated by the asterisk in $A$. The estimated reversal potential for a $\mathrm{Cl}^{-}$channel was $+68 \mathrm{mV}$. Basal current was subtracted.

cells, we used the vaccinia virus-T7 hybrid expression system developed by Elroy-Stein and co-workers (12). We have previously described the methods and the evidence that this system produces functional CFTR $(4,6,11)$. Briefly, HeLa cells were plated at $\sim 5 \times 10^{4}$ cells $/ \mathrm{cm}^{2}$ on collagen-coated plastic coverslips $24 \mathrm{~h}$ before infection. Recombinant vaccinia virus VTF7-3 (10-20 multiplicity of infection) was added to the cells for $1 \mathrm{~h}$ in serum-free media, and then cells were transfected with recombinant plasmids ( $5 \mu \mathrm{g}$ of plasmid $/ 10^{6}$ cells) with lipofectin $\left(20 \mu \mathrm{g}\right.$ of lipid $/ 10^{6}$ cells) and incubated at $37^{\circ} \mathrm{C}$. Cells were studied 10-18 h after transfection.

We also studied NIH 3T3 fibroblasts stably expressing CFTR (3T3CFTR cells). CFTR cDNA ( $4.5 \mathrm{~kb}$ from the initiating ATG to SacI site at nucleotide position 4622) was subcloned into a retroviral vector, the properties of which will be published elsewhere (Thompson, S., and R. C. Mulligan, submitted for publication). The resultant plasmid was cotransfected with pSV2 neo (13) into $\psi$ CRE cells (14). $48 \mathrm{~h}$ after trans- fection, cells were selected with $\mathrm{G} 418(1 \mathrm{mg} / \mathrm{ml})$. Medium harvested from G418-resistant cells was used to infect NIH 3T3 fibroblasts with a single 4-h exposure. The efficiency of infection was determined by Southern analysis: $\sim 80 \%$ of the NIH 3T3 cell population was found to contain an intact proviral genome. As a control, NIH 3T3 fibroblasts were exposed to medium harvested from nontransfected $\psi$ CRE cells.

Patch-clamp technique. The methods used for single channel patchclamp recording are similar to those previously described (15). Cells and bath were maintained at $30-35^{\circ} \mathrm{C}$ by a temperature-controlled microscope stage (Brook Industries, Lake Villa, IL). Pipette resistance was 2.5-6 M $\Omega$ and seal resistance was 2-25 G . In some cases higher resistance pipettes $(4.4-12.7 \mathrm{M} \Omega$ ) and seals $(3-110 \mathrm{G} \Omega)$ were used in an attempt to decrease the number of channels per patch. An amplifier (EPC 7; List Biological Laboratories, Campbell, CA) was used for current amplification and voltage clamping, and a laboratory computer system (Indec Systems Inc., Sunnyvale, CA) was used for data 
acquisition and analysis. Current amplitudes were determined from amplitude histograms. In current-voltage (I-V) relations, lines were fit either by eye or by linear regression. Currents were filtered at $1 \mathrm{kHz}$ and data was digitized at $2 \mathrm{kHz}$. Voltages are reported in reference to the external surface of the membrane and outward $(+)$ current refers to the flow of anions from the external to internal surface of the patch.

Chemicals and solutions. 3-isobutyl-1-methyl-xanthine (IBMX), forskolin, and adenosine 5'-triphosphate magnesium salt were obtained from Sigma Chemical Co., St. Louis, MO. Two types of the catalytic subunit of cAMP-dependent protein kinase were used with similar results. Catalytic subunit of PKA was obtained from Promega Biotec, Madison, WI. Recombinant catalytic subunit alpha of PKA was prepared using a full-length cDNA encoding the Chinese hamster enzyme (16) which was inserted into a bacterial expression vector (17). Recombinant catalytic subunit purified from the bacterial expression system was homogeneous as determined by polyacrylamide gel electrophoresis and exhibited a $K_{\mathrm{m}}$ of $18.6 \mu \mathrm{M}$ for Kemptide with a $V_{\max }$ of $10 \mu \mathrm{mol} /$ min per $\mathrm{mg}$.

Pipette solutions contained (in $\mathrm{mM}$ ): $\mathrm{NaCl}$ or $\mathrm{N}$-methyl-D-glucamine chloride (NMDG-Cl) (140), $\mathrm{MgCl}_{2}$ (1.2), $\mathrm{CaCl}_{2}$ (1.2), $N$-Tris(hydroxymethyl) methyl-2-aminoethane sulfonic acid (TES) (10), pH $=7.2$. In a few experiments the concentration of $\mathrm{MgCl}_{2}$ was $5 \mathrm{mM}$ and $\mathrm{CaCl}_{2}$ was $2 \mathrm{mM}$. Bath solutions contained (in $\mathrm{mM}$ ): $\mathrm{NaCl}, \mathrm{NaI}$, or NMDG-Cl (135), $\mathrm{MgCl}_{2}$ (2.4), EGTA (1), TES (10), dextrose (10), indomethacin $(3 \mu \mathrm{M}), \mathrm{pH}=7.2$. Aspartic acid replaced $\mathrm{Cl}^{-}$in bath and pipette solutions containing low $\mathrm{Cl}^{-}$. Final $\mathrm{Cl}^{-}$concentrations are indicated in the text or figure legends for the individual experiments.

\section{Results and Discussion}

Studies of cell-attached patches. A defining characteristic of macroscopic $\mathrm{Cl}^{-}$currents generated by expression of CFTR is their regulation by cAMP (4-8). Thus, to determine the single channel basis of the macroscopic $\mathrm{Cl}^{-}$current, we first asked whether an increase in intracellular cAMP would activate $\mathrm{Cl}^{-}$ channels in cell-attached membrane patches.

When we added $20 \mu \mathrm{M}$ forskolin and $100 \mu \mathrm{M}$ IBMX (to increase intracellular levels of cAMP), $\mathrm{Cl}^{-}$currents increased in 3T3-CFTR fibroblasts. Fig. $1 A$ shows a representative time course: current began to activate within $40 \mathrm{~s}$ of adding forskolin and IBMX and rapidly plateaued. When the agonists were removed, current returned to basal values within $100 \mathrm{~s}$. Current could be reversibly activated on repeated addition of agonist (Fig. $1 \mathrm{~A}$ ). In 17 of 18 patches from 3T3-CFTR cells, cAMP increased current by $39 \pm 27 \mathrm{pA}($ mean \pm SEM) within $77 \pm 52 \mathrm{~s}$. When agonists were removed, current returned to baseline in 10 of 10 patches. A second stimulation with cAMP increased current in two of two experiments.

The tracings in Fig. $1 B$ show that cAMP-activated currents appeared noisy and often wavy, suggesting that multiple, low conductance channels were present in the membrane patch. Similar results were obtained with CFTR expressed in insect cells (7). In such tracings it was not possible to discern discrete single channel events; however, examination of the reversal potential in I-V relations, indicated that current flowed through $\mathrm{Cl}^{-}$channels. Fig. $1 C$ shows the $\mathrm{I}-\mathrm{V}$ relation when the pipette contained $142 \mathrm{mM} \mathrm{Cl}^{-}$; the reversal potential was $3 \pm 3$ $\mathrm{mV}$ (in five experiments with these solutions). If the current were carried by $\mathrm{Cl}^{-}$, we would expect a reversal potential near this value, based on an estimated intracellular $\mathrm{Cl}^{-}$concentration of $40 \mathrm{mM}$ and an estimated membrane voltage of $-40 \mathrm{mV}$ (18). Rectification in the I-V relation at negative voltages is consistent with a lower intracellular than extracellular $\mathrm{Cl}^{-}$concentration. When the pipette solution $\mathrm{Cl}^{-}$concentration was
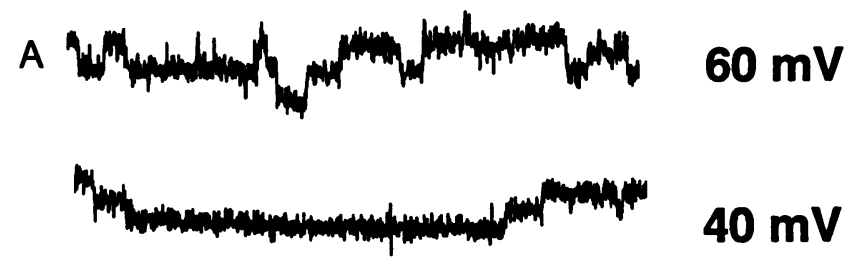

$40 \mathrm{mV}$

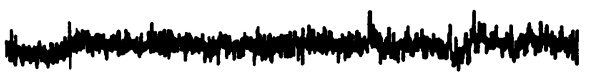

$20 \mathrm{mV}$

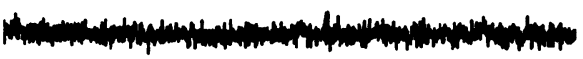

$\mathrm{O} \mathrm{mV}$

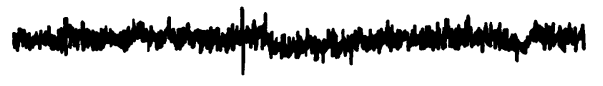

$-20 \mathrm{mV}$



\section{$-40 \mathrm{mV}$}



$-60 \mathrm{mV}$

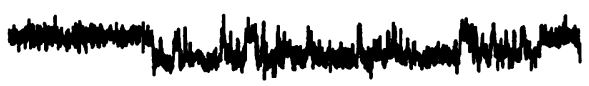

$-80 \mathrm{mV}$
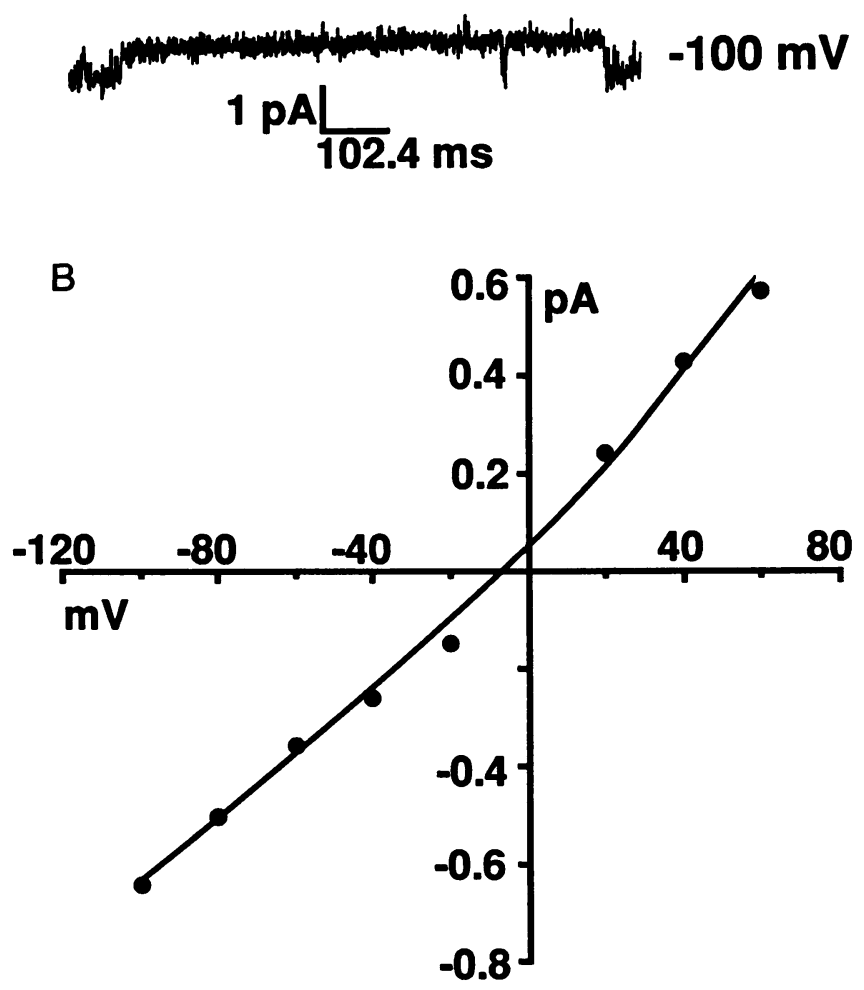

Figure 3. Single-channel currents from a cell-attached patch in a 3T3-CFTR fibroblast. Pipette solution contained $140 \mathrm{mM}$ NMDG-Cl (estimated reversal potential for $\mathrm{a} \mathrm{Cl}^{-}$channel was $0 \mathrm{mV}$ ). ( $A$ ) Cellattached, single channel tracings at the voltages indicated. $(B) \mathrm{I}-\mathrm{V}$ relation of channel in $A$. Single-channel conductance was $8.6 \mathrm{pS}$ at positive voltages and $6.2 \mathrm{pS}$ at negative voltages. 


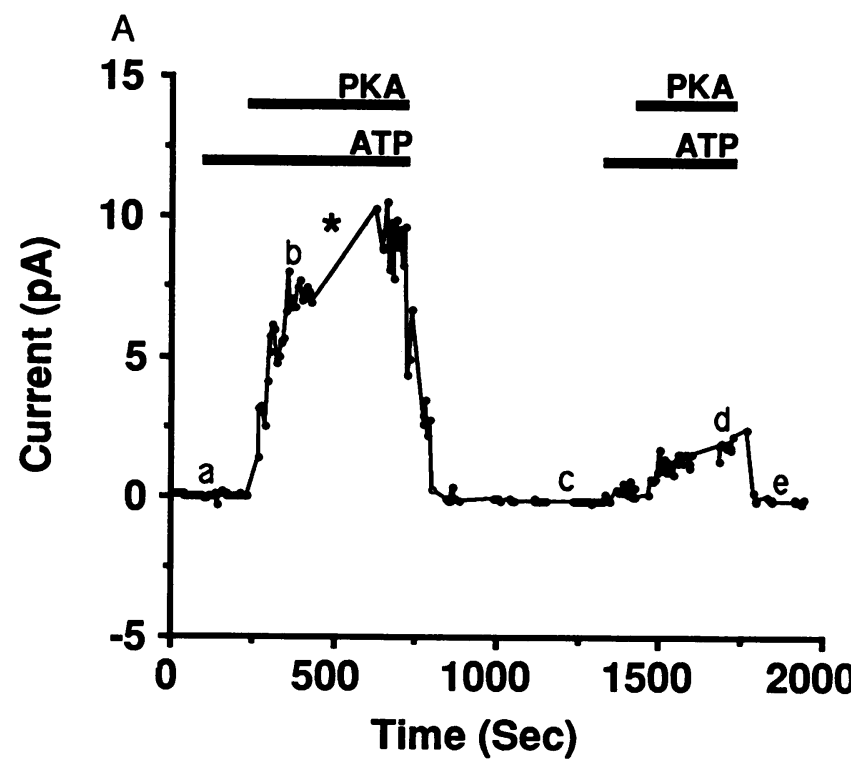

a

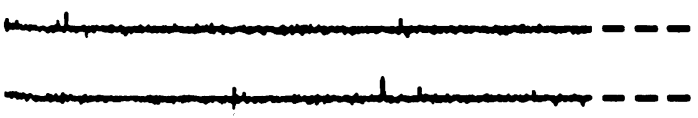

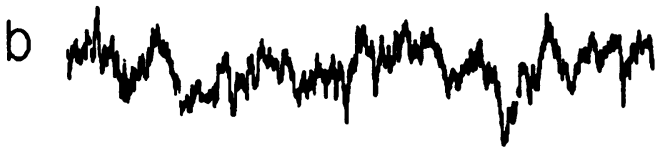


Figure 4. Activation of $\mathrm{Cl}^{-}$channels in an excised, inside-out patch from a 3T3-CFTR fibroblast. External (pipette) solution contained $142 \mathrm{mM} \mathrm{Cl}^{-}$and $140 \mathrm{mM} \mathrm{NMDG}$; bath contained $140 \mathrm{mM} \mathrm{Cl}^{-}$and $141 \mathrm{mM} \mathrm{Na}^{+}$. $(A)$ Time course for activation and reversal of currents; bars indicate times during which catalytic subunit of PKA (75 nM) and ATP $(1 \mathrm{mM})$ were present in the internal solution. *Time during which data shown in Fig. 8 was obtained. Data are average currents during a 1-s pulse to $+40 \mathrm{mV}$ from a holding voltage of $0 \mathrm{mV}$. (B) Representative current traces obtained at the times indicated by lowercase letters in $\mathrm{A}$.

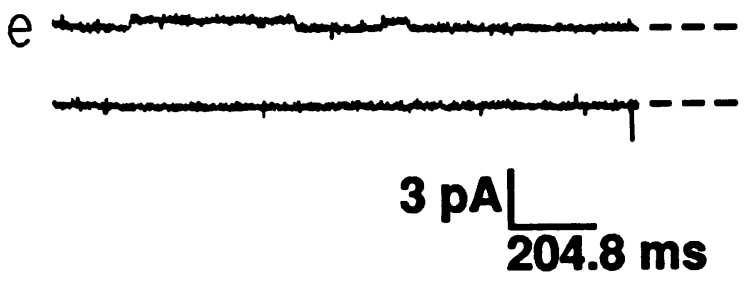


reduced from 142 to $15.5 \mathrm{mM}$, the reversal potential shifted to $+47 \pm 7 \mathrm{mV}(n=5)$ as expected for $\mathrm{a} \mathrm{Cl}^{-}$selective channel (Fig. $1 C$ ). In contrast, when $\mathrm{Na}^{+}$was substituted for NMDG in the pipette solution, the reversal potential did not change $(n=6$, not shown).

We found similar results in HeLa cells transiently expressing CFTR. Fig. $2 A$ shows that forskolin and IBMX reversibly stimulated current. Fig. $2 B$ shows representative current tracings; as observed with 3T3-CFTR fibroblasts, multiple channels were contained in the patch and single channels were not readily resolved. IBMX and forskolin activated current within $67 \pm 10 \mathrm{~s}$ in 3 of 12 cell-attached patches and the effect was reversible in 2 of the 3 patches. This frequency of expression is consistent with the heterogeneous vaccinia virus/ $\mathrm{T} 7$ expression system $(4,6)$. Fig. $2 C$ shows that the I-V relation reversed at a positive voltage, as expected for a $\mathrm{Cl}^{-}$selective channel (the pipette contained $14 \mathrm{mM} \mathrm{Cl}^{-}$; the estimated reversal potential for a $\mathrm{Cl}^{-}$channel was $+68 \mathrm{mV}$ ).

Although most patches contained multiple channels, we did observe single channel currents in six cell-attached patches from 3T3-CFTR cells stimulated with forskolin and IBMX (no channel activity was observed before stimulation). Fig. $3 \mathrm{~A}$ shows representative current tracings; Fig. $3 B$ shows the single channel I-V relation. In cell-attached patches with a pipette $\mathrm{Cl}^{-}$ concentration of $140 \mathrm{mM}$, the single channel conductance at positive voltages was $8.6 \pm 0.3 \mathrm{pS}$ and at negative voltages was $5.6 \pm 1.4 \mathrm{pS}(n=5)$.

These data indicate that cAMP reversibly activated a low conductance $\mathrm{Cl}^{-}$channel in cell-attached membrane patches.

Studies of excised, cell-free patches. To more precisely determine the conductive properties of CFTR-generated $\mathrm{Cl}^{-}$ channels and to investigate their regulation by phosphorylation, we turned to excised, cell-free patches. Fig. $4 A$ shows the time course of current activation in a patch from a 3T3-CFTR cell. Addition of ATP $(1 \mathrm{mM})$ did not activate current during $130 \mathrm{~s}$ of observation, but within $34 \mathrm{~s}$ of adding the catalytic subunit of PKA (in the continued presence of ATP), current increased. Fig. $4 B$ shows representative current tracings obtained at the times indicated in Fig. $4 \mathrm{~A}$ : the currents had a wavy, noisy pattern consistent with the presence of multiple channels in the patch and similar to what we had observed in cell-attached patches. Activation required the combination of the catalytic subunit of PKA and ATP; addition of either alone was insufficient. When we removed PKA and ATP, current decreased to basal levels. During basal conditions, we only rarely observed channel openings; Fig. $4 B$ (parts $c$ and $e$ ) show examples. When we once again added PKA and ATP to the cytosolic surface of the patch, the channels reactivated. PKA and ATP activated channels in 40 of 55 patches with current increasing by $25 \pm 21 \mathrm{pA}$. Activation reversed when the agonists were removed in 27 of 27 patches and a second stimulation increased current in 13 of 13 patches. The average time from addition of PKA and ATP until channels were activated was $73 \pm 71 \mathrm{~s}$.

It is interesting that the second addition of PKA and ATP activated less $\mathrm{Cl}^{-}$current than the first. We observed the same phenomena on increasing intracellular CAMP in cell-attached patches (Fig. $1 A$ ) and in whole cell patch-clamp studies (6).

Fig. 5 shows I-V relations from a multichannel excised, inside-out patch. In the presence of symmetrical and asymmet-

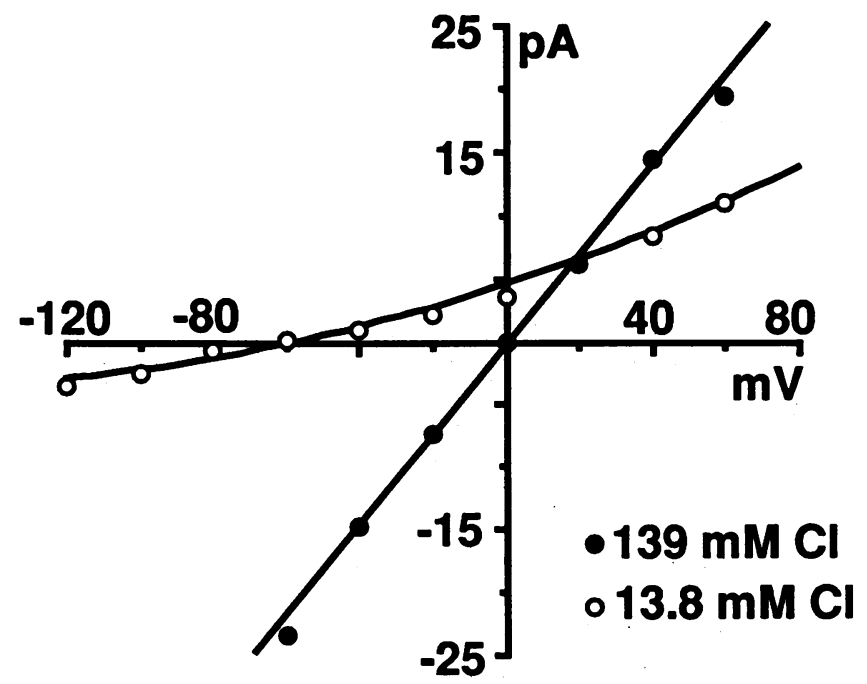

Figure 5. I-V relation of currents activated by PKA and ATP in an excised, inside-out patch. External solution contained $142 \mathrm{mM} \mathrm{Cl}^{-}$ for both I-V relations. For current shown by solid symbols, internal solution contained $139 \mathrm{mM} \mathrm{Cl}^{-}$; for current shown by open symbols, internal solution contained $13.8 \mathrm{mM} \mathrm{Cl}^{-}$. Data are from the same patch. Currents represented by open symbols were obtained during a second application of PKA and ATP, which explains the lower absolute values of current (see text). The expected shift in reversal potential for a $\mathrm{Cl}^{-}$selective channel was $+62 \mathrm{mV}$; the observed shift was $+60 \mathrm{mV}$. We were able to produce similar shifts in the reversal potential in seven other patches.

rical $\mathrm{Cl}^{-}$concentrations, the reversal potential shifted as expected for a $\mathrm{Cl}^{-}$-selective channel.

Just as with cell-attached patches, it was difficult to obtain excised patches that contained a small enough number of channels to observe single channel events. To reduce the number of channels per patch, we used smaller pipettes and were then able to observe single channel events in some cases. Fig. $6 \mathrm{~A}$ shows an example from a patch in which at least three channels were activated within $85 \mathrm{~s}$ after addition of ATP and catalytic subunit of PKA.

The I-V relation for the single channel (Fig. $6 \mathrm{~B}$ ) was linear in symmetrical $\mathrm{Cl}^{-}$concentrations and the single channel conductance was $10 \mathrm{pS}$. Using high resistance pipettes, we observed single channel events at a complete series of voltages in seven patches activated by PKA and ATP: average single channel conductance was $10.4 \pm 0.2 \mathrm{pS}^{2}$. Fig. $6 \mathrm{~B}$ also shows that when the intracellular (bath) solution was exchanged for a low $\mathrm{Cl}^{-}$concentration $(n=4)$, the reversal potential shifted as expected for a $\mathrm{Cl}^{-}$-selective channel. Because of the small single channel conductance, we could not reliably determine the reversal potential from single channel traces; reversal potentials and selectivity are more reliably determined from the multichannel patches. We were also sometimes able to observe single channel events in patches containing a large number of chan-

2. Single channel conductance $(7.4 \pm 0.5 \mathrm{pS}, n=5)$ was lower in a 10-mM Hepes buffer than in a TES buffer. The inhibitory effect of Hepes on $\mathrm{Cl}^{-}$channels has been reported previously $(27,28)$. 


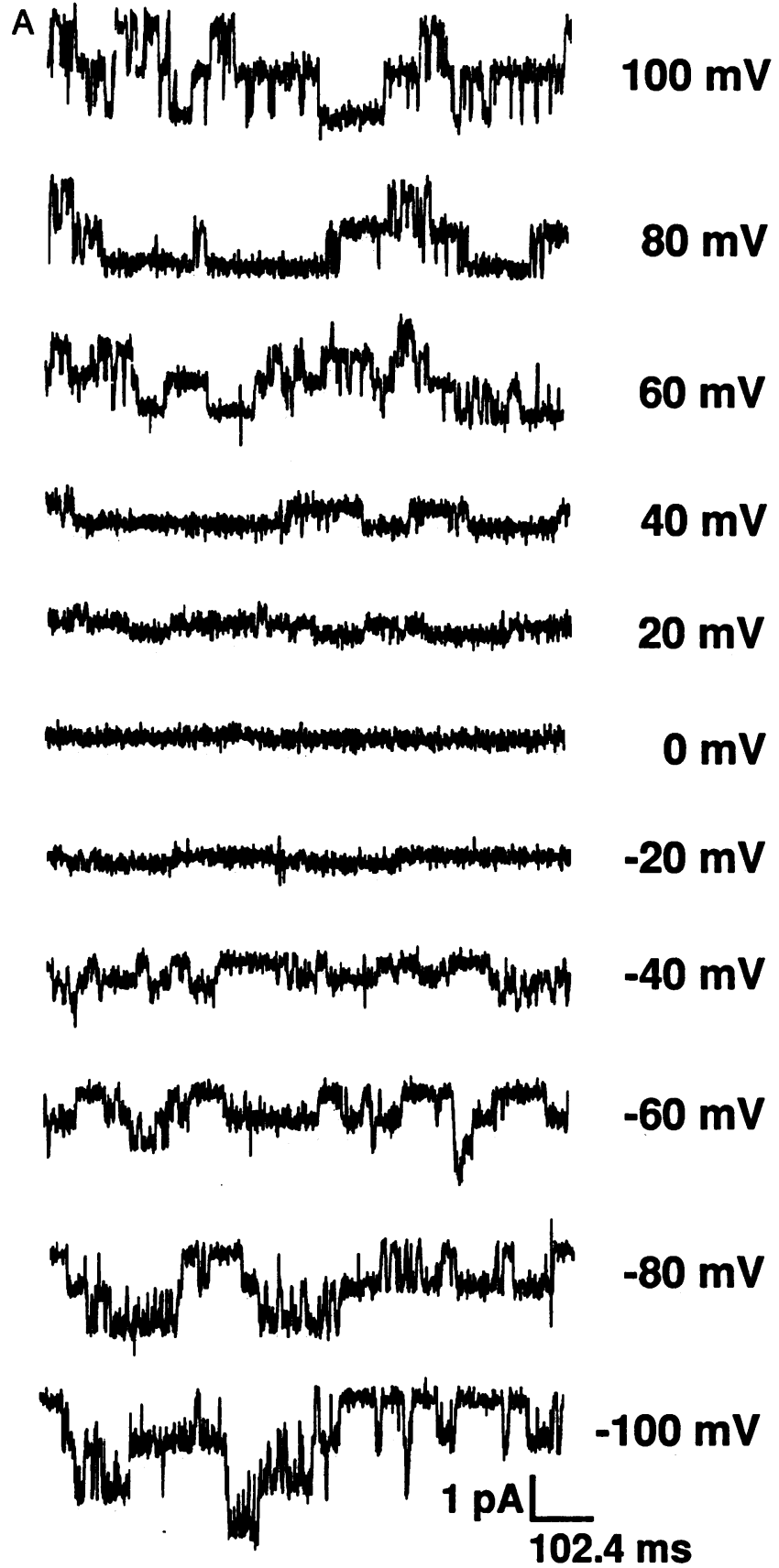

nels: after we removed forskolin and IBMX from cell-attached patches or PKA and ATP from excised patches, we sometimes saw unitary events as the current decreased toward basal levels. These currents always had the same conductive and permeability properties as those observed in patches that only contained a few channels. ${ }^{3}$

3. Given the values of single-channel conductance, the minimum number of channels required to produce the increase in current with stimulation was $85 \pm 62$ channels in cell-attached patches and $63 \pm 52$ channels in excised patches. The actual number of channels was obviously much higher because the open state probability was $<1$. Because of the substantial number of channels per patch we could not accurately determine open state probability or number of channels.

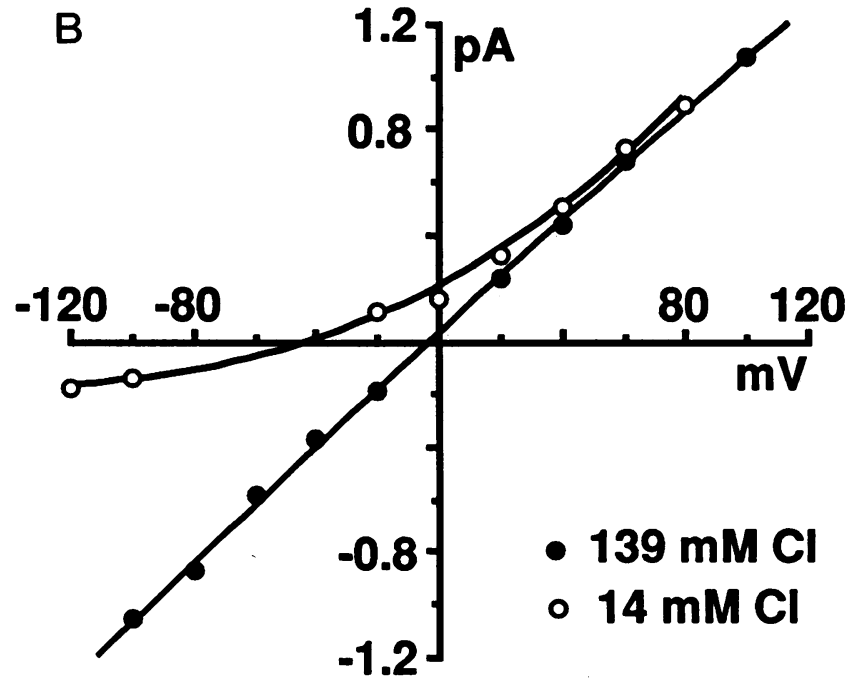

Figure 6. Single channel current activated by PKA and ATP in an excised, inside-out patch. $(A)$ Tracings were obtained from a 3T3CFTR fibroblast after addition of catalytic subunit of PKA (75 nM) and ATP (1 mM); no channel activity was obtained before addition of both agents. Tracings were obtained at the indicated voltages. Pipette contained $142 \mathrm{mM} \mathrm{Cl}^{-}$and $140 \mathrm{mM}$ NMDG; bath contained $139 \mathrm{mM} \mathrm{Cl}^{-}$and $144 \mathrm{mM}$ NMDG. (B) I-V relation for channel shown in $A$ is shown by solid symbols. Open symbols show data obtained after reduction of bath $\mathrm{Cl}^{-}$concentration to $14{\mathrm{mM}\left(\mathrm{Cl}^{-} \text {was }\right.}^{-}$ replaced by aspartic acid, expected reversal potential for $\mathrm{Cl}^{-}$current is $-62 \mathrm{mV}$ ).

Fig. $7 \mathrm{~A}$ shows that the channel was selective for $\mathrm{Cl}^{-}$: substitution of internal $\mathrm{Na}^{+}$for NMDG did not alter the $\mathrm{I}-\mathrm{V}$ relation. We found similar results in multichannel patches $(n=8)$. We previously showed that the CFTR-generated macroscopic $\mathrm{Cl}^{-}$ currents in the whole cell were more permeable to $\mathrm{Cl}^{-}$than to $I^{-}$(8); Fig. 7, $A$ and $B$, shows that this was also the case for channels activated by PKA in excised patches. The calculated selectivity ratio of $\mathrm{I}^{-}$to $\mathrm{Cl}^{-}\left(\mathrm{P}_{\mathrm{I}} / \mathrm{P}_{\mathrm{Cl}}\right)$ was $0.42 \pm 0.06(n=3)$; in good agreement with values obtained from whole cell and apical membrane studies: $P_{1} / P_{C}$ was $\sim 0.57(8)$. In addition, as we previously reported for whole-cell studies (8), the conductance was less in $\mathrm{I}^{-}$than in $\mathrm{Cl}^{-}$.

Channels activated in excised patches by PKA and ATP showed no discernible time-dependent voltage effects. Fig. 8 

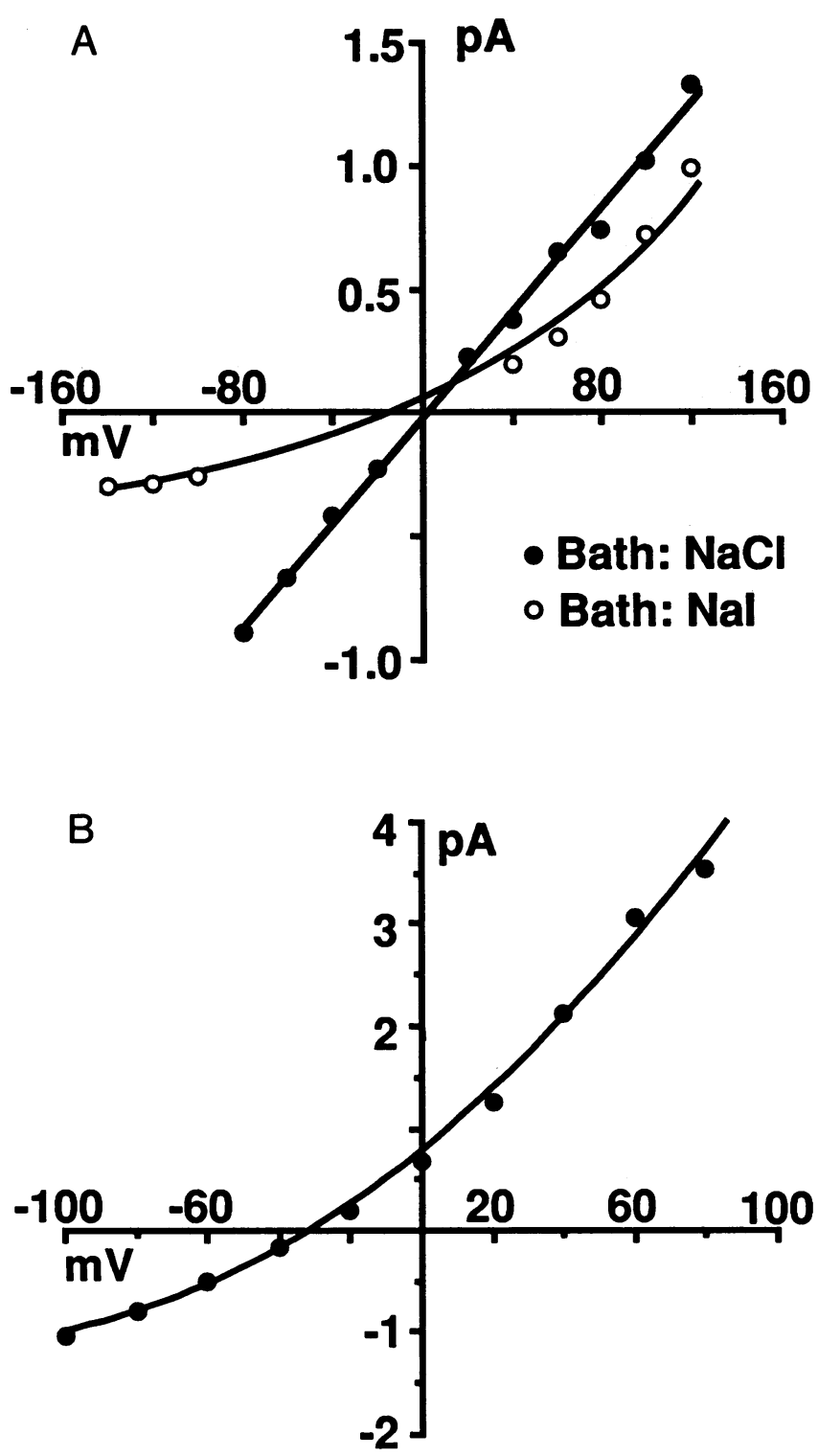

Figure 7. I-V relations of $\mathrm{Cl}^{-}$channels stimulated with PKA and ATP in excised patches. $(A)$ Data are from single channel currents. Pipette contained $142 \mathrm{mM} \mathrm{Cl}^{-} / 140 \mathrm{mM}$ NMDG; bath (internal solution) contained either $140 \mathrm{mM} \mathrm{Cl}^{-} / 141 \mathrm{mM} \mathrm{Na}$ (solid symbols) or $135 \mathrm{mM}$ $\mathrm{I} / 143 \mathrm{mM} \mathrm{Na}$ (open symbols). (B) Data are from a multichannel patch. Pipette contained $142 \mathrm{mM} \mathrm{Cl}-140 \mathrm{mM}$ NMDG; bath contained $135 \mathrm{mM} / 143 \mathrm{mM} \mathrm{Na}$. $\mathrm{P}_{\mathrm{I}} / \mathrm{P}_{\mathrm{C}}$ was 0.34 .

shows individual traces from a multichannel patch (Fig. $8 \mathrm{~A}$ ) and an ensemble average (Fig. $8 \mathrm{~B}$ ) of such traces taken during steps to $\pm 100 \mathrm{mV}$ from a holding voltage of $0 \mathrm{mV}$. There is no time-dependent increase or decrease in current at either voltage. Similar results were obtained in three patches and also when voltage-dependence was tested at $\pm 80 \mathrm{mV}$ or at $\pm 60 \mathrm{mV}$. Similar results were obtained with cell-attached patches (not shown). These results are consistent with studies of CFTR-generated currents using the whole cell patch-clamp technique: minimal, if any, voltage-dependence was observed (4-8). We did not observe activation of $\mathrm{Cl}^{-}$channels by membrane depo- larization, as has been observed with outwardly rectifying $\mathrm{Cl}^{-}$ channels (19).

Our previous studies using the whole cell patch-clamp technique and a fluorescent microscopic technique showed that 3T3 fibroblasts and HELA cells do not normally contain cAMP-regulated $\mathrm{Cl}^{-}$channels (6). That observation was confirmed in cell-attached patches (an increase in cAMP failed to elicit $\mathrm{Cl}^{-}$current in 3 of 3 patches from control $3 \mathrm{~T} 3$ fibroblasts, compared to 1 of 17 experiments on 3T3-CFTR cells, $P$ $=0.003$ by chi-square analysis), and in excised patches (PKA and ATP failed to elicit $\mathrm{Cl}^{-}$currents in 4 of 4 patches, compared with 15 of 55 patches from 3T3-CFTR cells, $P<0.02$ ).

Relationship of CFTR-generated $\mathrm{Cl}^{-}$channels to other $\mathrm{Cl}^{-}$ channels. Some of the single-channel properties of CFTR which we report are similar to those reported by Kartner et al. (7); when CFTR was expressed in insect cells, they found that the I-V relation was linear with a single channel conductance of 8.4 pS, the channel was observed more frequently in cAMP-stimulated cells, and $\mathrm{I}^{-}$was more permeable than $\mathrm{Cl}^{-}\left(\mathrm{P}_{\mathrm{I}} / \mathrm{P}_{\mathrm{Cl}}\right.$

A



B
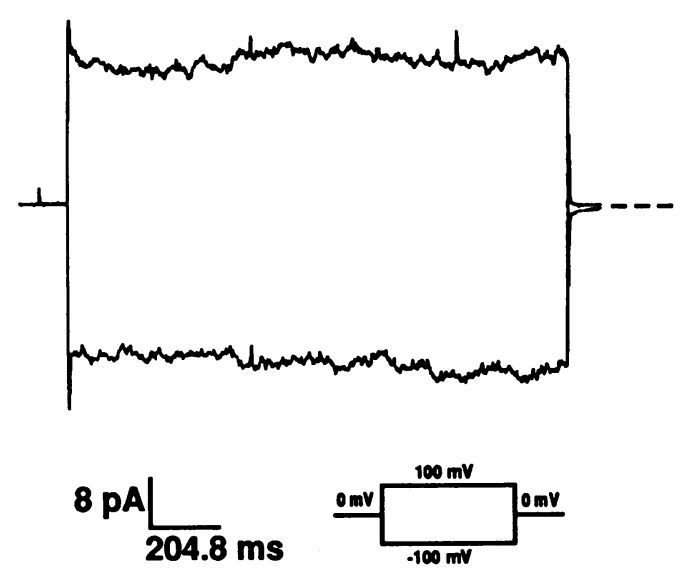

Figure 8. Effect of voltage on $\mathrm{Cl}^{-}$current in symmetrical $\mathrm{Cl}^{-}$concentrations. Data are from experiments shown in Fig. 4. $(A)$ Two tracings from an excised, inside-out patch in which $\mathrm{Cl}^{-}$channels were activated by addition of catalytic subunit of PKA and ATP. Dashed line indicates zero current. Voltage was held at $0 \mathrm{mV}$ and then alternately stepped to $\pm 100 \mathrm{mV}$. (B) Ensemble of seven sweeps like those shown in $A$. Absolute value of current was not significantly different at either voltage and we observed no time-dependent changes. This observation, together with the observation of linear I-V relation, indicates that there are no appreciable time-dependent voltage effects. 
$=1.2)$. The difference in anion selectivity from values we report $\left(\mathrm{P}_{\mathrm{I}} / \mathrm{P}_{\mathrm{Cl}}=0.42\right)$ is not readily explained by the anion concentration gradients or $\mathrm{pH}$ (unpublished data). The anion selectivity we report for recombinant CFTR is consistent with that of native CFTR in the apical membrane of T84 cells and human airway epithelia $(8,20)$, in whole cell patch-clamp studies of T84 cells (21), in sweat gland duct cells (22), and in two different cell types using two different expression systems (8). Moreover, mutation of CFTR altered its anion selectivity (8).

The single channel properties of CFTR-generated $\mathrm{Cl}^{-}$ channel, which we report here, are different from those of the outwardly rectifying $\mathrm{Cl}^{-}$channel (reviewed in [19]). The CFTR-generated $\mathrm{Cl}^{-}$channel has a linear I-V relation and single channel conductance of $10 \mathrm{pS}$, whereas the outwardly rectifying $\mathrm{Cl}^{-}$channel has a single channel conductance of $\sim 30$ $50 \mathrm{pS}$. In addition, the outwardly rectifying $\mathrm{Cl}^{-}$channel is more permeable to $\mathrm{I}^{-}$than to $\mathrm{Cl}^{-}$, whereas the CFTR $\mathrm{Cl}^{-}$channel is more permeable to $\mathrm{Cl}^{-}$than to $\mathrm{I}^{-}(8,20)$. The outwardly rectifying $\mathrm{Cl}^{-}$channel is also activated by prolonged periods of strong membrane depolarization: after activation by strong membrane depolarization the channel remains in an activated state. In contrast, CFTR-generated $\mathrm{Cl}^{-}$channels were not activated by membrane depolarization; they were only activated by cAMP in cell-attached patches or by the catalytic subunit of PKA in excised patches. Moreover, such activation was reversible. Thus, the CFTR-generated $\mathrm{Cl}^{-}$channel and the outwardly rectifying $\mathrm{Cl}^{-}$channel are most likely two different channels. How then can one reconcile previous studies showing defective regulation of the outwardly rectifying $\mathrm{Cl}^{-}$channel in $\mathrm{CF}$ epithelia with the CFTR $\mathrm{Cl}^{-}$channel? We do not know the answer. One possibility is that physiologic abnormalities resulting from mutations in CFTR somehow produce defective (secondary) regulation of other channels. A problem that is perhaps similar is to understand how mutations in CFTR (i.e., a defect in $\mathrm{Cl}^{-}$ channel function) produce the wide variety of other phenotypic manifestations in $\mathrm{CF}$.

The CFTR-generated $\mathrm{Cl}^{-}$channel also has different properties from $\mathrm{Ca}^{2+}$-activated and volume-activated $\mathrm{Cl}^{-}$channels in epithelia $(20,21)$ : the most obvious differences are in regulation and anion selectivity. Of note, the CFTR-generated $\mathrm{Cl}^{-}$ channels are not dependent on internal $\mathrm{Ca}^{2+}$ (our internal solution was $\mathrm{Ca}^{2+}$-free), an observation consistent with previous observations that $\mathrm{Ca}^{2+}$ and cAMP activate two different types of apical membrane $\mathrm{Cl}^{-}$channels (20).

The properties of CFTR-generated $\mathrm{Cl}^{-}$channels are similar to those of an 8.6-pS channel with a linear I-V relation studied in cell-attached patches from T84 cells (23). That channel was observed with a higher frequency in patches from cAMP-stimulated cells and it had no time-dependent voltage effects, but anion selectivity was not determined. A 4-7-pS channel with a linear I-V was also observed in pancreatic duct epithelium (2425). That channel was stimulated by cAMP in cell-attached patches, but the anion selectivity was different: $\mathrm{Br}^{-} \simeq \mathrm{I}^{-} \simeq \mathrm{Cl}^{-}$. Other $\mathrm{Cl}^{-}$channels have also been reported (26), but their relationship to the present data is uncertain.

Summary. These data identify the single channel properties of CFTR-generated $\mathrm{Cl}^{-}$channels. The channel has a conductance of $\sim 10 \mathrm{pS}$, displays a linear I-V relation when studied in symmetrical $\mathrm{Cl}^{-}$concentrations, shows minimal time-dependent voltage effects, and is more permeable to $\mathrm{Cl}^{-}$than to $\mathrm{I}^{-}$.
Our data also indicate that these channels are activated by phosphorylation with PKA. These data set the stage for further studies into the biophysical properties of CFTR and its regulation.

\section{Acknowledgments}

We thank Phil Karp, Aurita Puga and Theresa Mayhew for technical assistance.

H. A. Berger was supported by an American Heart Association, Iowa Affiliate, Fellowship Award. This work was supported in part by grants from the National Heart, Lung, and Blood Institute (HL42385) and the National Cystic Fibrosis Foundation.

\section{References}

1. Boat, T. F., M. J. Welsh, and A. L. Beaudet. 1989. Cystic Fibrosis. In The Metabolic Basis of Inherited Disease. C. R. Scriver, A. L. Beaudet, W. S. Sly, and D. Valle, editors. McGraw-Hill, Inc., New York. 2649-2680.

2. Quinton, P. 1990. Cystic fibrosis: a disease in electrolyte transport. FASEB (Fed. Am. Soc. Exp. Biol.) J. 4:2709-2717.

3. Riordan, J. R., J. M. Rommens, B.-S. Kerem, N. Alon, R. Rozmahel, Z. Grzelczek, J. Zielenski, S. Lok, N. Plavsic, J.-L. Chou, et al. 1989. Identification of the cystic fibrosis gene: cloning and characterization of complementary DNA. Science (Wash. DC). 245:1066-1073.

4. Rich, D. P., M. P. Anderson, R. J. Gregory, S. H. Cheng, S. Paul, D. M. Jefferson, J. D. McCann, K. W. Klinger, A. E. Smith, and M. J. Welsh. 1990. Expression of cystic fibrosis transmembrane conductance regulator corrects defective chloride channel regulation in cystic fibrosis airway epithelial cells. Nature (Lond.). 347:358-363.

5. Drumm, M. L., H. A. Pope, W. H. Cliff, J. M. Rommens, S. A. Marvin, L.-C. Tsui, F. C. Collins, R. A. Frizzell, and J. M. Wilson. 1990. Correction of the cystic fibrosis defect in vitro by retrovirus-mediated gene transfer. Cell. 62:12271233.

6. Anderson, M. P., D. R. Rich, R. J. Gregory, A. E. Smith, and M. J. Welsh. 1991. Generation of cAMP-activated chloride currents by expression of CFTR. Science (Wash. DC). 251:679-682.

7. Kartner, N., J. W. Hanrahan, T. J. Jensen, A. L. Naismith, S. Sun, C. A Ackerley, E. F. Reyes, L.-C. Tsui, J. M. Rommens, C. E. Bear, and J. R. Riordan. 1991. Expression of the cystic fibrosis gene in non-epithelial invertebrate cells produces a regulated anion conductance. Cell. 64:681-691.

8. Anderson, M. P., R. J. Gregory, S. Thompson, D. W. Souza, S. Paul, R. C. Mulligan, A. E. Smith, and M. J. Welsh. 1991. Demonstration that CFTR is a chloride channel by alteration of its anion selectivity. Science (Wash. DC). 253:202-205.

9. Rich, D. P., R. J. Gregory, M. P. Anderson, P. Manavalan, A. E. Smith, and M. J. Welsh. 1991. Effect of deleting the R domain on CFTR-generated chloride channels. Science (Wash. DC). 253:205-207.

10. Kaupp, U. B. 1991. The cyclic nucleotide-gated channels of vertebrate photoreceptors and olfactory epithelium. Trends Neurosci. 14:150-157.

11. Gregory, R. J., S. H. Cheng, D. R. Rich, J. Marshall, S. Paul, K. Hehir, L. Ostedgaard, K. W. Klinger, M. J. Welsh, and A. E. Smith. 1990. Expression and characterization of the cystic fibrosis transmembrane conductance regulator. $\mathrm{Na}$ ture (Lond.). 347:382-386.

12. Elroy-Stein, O., T. R. Fuerst, and B. Moss. 1989. Cap-independent translation of mRNA conferred by encephalomyocarditis virus 5 ' sequence improves the performance of the vaccinia virus/bacteriophage T7 hybrid system. Proc. Natl. Acad. Sci. USA. 86:6126-6130.

13. Southern, P. J., and P. J. Berg. 1982. Transformation of mammalian cells to antibiotic resistance with a bacterial gene under control of the SV40 early region promoter. J. Mol. Appl. Genet. 1:327-341.

14. Danos, O., and R. C. Mulligan. 1988. Safe and efficient generation of recombinant retroviruses with amphotropic and ecotropic range hosts. Proc. Natl. Acad. Sci. USA. 85:6460-6464.

15. Hamill, O. P., A. Marty, E. Neher, B. Sakmann, and F. J. Sigworth. 1981. Improved patch-clamp techniques for high-resolution current recording from cells and cell-free membrane patches. Pfluegers Arch. Eur. J. Physiol. 391:85100.

16. Howard, P., K. H. Day, K. E. Kim, J. Richardson, J. Thomas, I. Abraham, R. Fleischman, M. Gottesman, and R. A. Maurer. 1991. Decreased catalytic 
subunit mRNA levels and altered catalytic subunit mRNA structure in a cAMPresistant chinese hamster ovary cell line. J. Biol. Chem. In press.

17. Studier, F. W., A. H. Rosenberg, J. J. Dunn, and J. W. Dubendorff. 1990 Use of T7 RNA polymerase to direct expression of cloned genes. Methods Enzymol. 185:60-89.

18. Welsh, M. J. 1987. Electrolyte transport by airway epithelia. Physiol. Rev. 67:1143-1184

19. Welsh, M. J. 1990. Abnormal regulation of ion channels in cystic fibrosis epithelia. FASEB (Fed. Am. Soc. Exp. Biol.) J. 4:2718-2725.

20. Anderson, M. P., and M. J. Welsh. 1991. Calcium and cAMP activate different chloride channels in the apical membrane of normal and cystic fibrosis epithelia. Proc. Natl. Acad. Sci. USA. 88:6003-6007.

21. Cliff, W. H., and R. A. Frizzell. 1990. Separate $\mathrm{Cl}^{-}$conductances activated by cAMP and $\mathrm{Ca}^{2+}$ in $\mathrm{Cl}^{-}$-secreting epithelial cells. Proc. Natl. Acad. Sci. USA. 87:4956-4960.

22. Quinton, P. M., and M. M. Reddy. 1989. $\mathrm{Cl}^{-}$conductance and acid secretion in the human sweat duct. In Bicarbonate, Chloride, and Proton Transport Systems. J. H. Durham and M. A. Hardy, editors. The New York Academy of Sciences, New York. 438-446.
23. Tabcharani, J. A., W. Low, D. Elie, and J. W. Hanrahan. 1990. Low-conductance chloride channel activated by cAMP in the epithelial cell line T84. FEBS (Fed. Eur. Biochem. Soc.) Lett. 270:157-164.

24. Gray, M. A., A. Harris, L. Coleman, J. R. Greenwell, and B. E. Argent. 1989. Two types of chloride channel on duct cells cultured from human fetal pancreas. Am. J. Physiol.: Cell. 257:C240-C251.

25. Gray, M. A., C. E. Pollard, A. Harris, L. Coleman, J. R. Greenwell, and B. E. Argent. 1991. Anion selectivity and block of the small conductance chloride channel on pancreatic duct cells. Am. J. Physiol.: Cell. 259:C752-C761.

26. Frizzell, R. A., and D. R. Halm. 1990. Chloride channels in epithelial cells. In Current Topics in Membranes and Transport. Academic Press, New York. 247-282.

27. Hanrahan, J. W., and J. A. Tabcharani. 1990. Inhibition of an outwardly rectifying anion channel by HEPES and related buffers. J. Membr. Biol. 116:6577.

28. Yamamoto, D., and N. Suzuki. 1987. Blockage of chloride channels by HEPES buffer. Proc. R. Soc. Lond. B Biol. Sci. 230:93-100. 